\title{
An Integrated Method of Data Mining and Flow Unit Identification for Typical Low Permeability Reservoir Prediction
}

\author{
Peng Yu $\mathbf{u}^{1,2}$ \\ ${ }^{1}$ Guangxi Colleges and Universities Key Laboratory of Beibu Gulf Oil and Natural Gas Resource Effective Utilization, \\ Beibu Gulf University, Qinzhou, China \\ ${ }^{2}$ College of Petroleum and Chemical Engineering, Beibu Gulf Universtiy, Qinzhou, China \\ Email: developoil@163.com
}

How to cite this paper: Yu, P. (2019) An Integrated Method of Data Mining and Flow Unit Identification for Typical Low Permeability Reservoir Prediction. World Journal of Engineering and Technology, 7, 122-128.

https://doi.org/10.4236/wjet.2019.71008

Received: December 29, 2018

Accepted: January 25, 2019

Published: January 28, 2019

Copyright $\odot 2019$ by author(s) and Scientific Research Publishing Inc. This work is licensed under the Creative Commons Attribution International License (CC BY 4.0).

http://creativecommons.org/licenses/by/4.0/

\begin{abstract}
With the development of oilfield exploration and mining, the research on continental oil and gas reservoirs has been gradually refined, and the exploration target of offshore reservoir has also entered the hot study stage of small sand bodies, small fault blocks, complex structures, low permeability and various heterogeneous geological bodies. Thus, the marine oil and gas development will inevitably enter the complicated reservoir stage; meanwhile the corresponding assessment technologies, engineering measures and exploration method should be designed delicately. Studying on hydraulic flow unit of low permeability reservoir of offshore oilfield has practical significance for connectivity degree and remaining oil distribution. An integrated method which contains the data mining and flow unit identification part was used on the flow unit prediction of low permeability reservoir; the predicted results were compared with mature commercial system results for verifying its application. This strategy is successfully applied to increase the accuracy by choosing the outstanding prediction result. Excellent computing system could provide more accurate geological information for reservoir characterization.
\end{abstract}

\section{Keywords}

Low Permeability Reservoir, Offshore Oilfield, Hydraulic Flow Unit, Flow Unit Identification, Data Mining

\section{Introduction}

With the exploration and mining in marine oil and gas formation, there are an 
increasing number of low permeability reservoirs being found. Generally speaking, this type of reservoir has the serious heterogeneity characteristics which can lead to the larger difference of permeability among reservoirs of equal porosity basically, and several related logging response characteristics are not obvious. In such environment, a reasonable representation of the reservoir has very important practical significance. In order to characterize oil and gas reservoirs more precisely, the concept of reservoir hydraulic flow unit is introduced, which, after continued development and improvement, for the moment generally refers to the basic unit with consistent petrological, geological and hydrodynamic characteristics within a given reservoir that is different from other rocks, and this method is especially effective for the porous medias paces with strong heterogeneity characteristics [1] [2] [3] [4].

Reservoir quality index and flow unit are two basic concepts used by scholars. Both petroleum geologists and engineers have long acquainted the importance of these concepts in petroleum field as they have applied them as outstanding methods to properly quantify and characterize reservoir formations [5]. Recent studies also have proved the superiority of data mining technology to empirical and statistical approaches in petroleum and geosciences related problems. A growing tendency utilizing mining algorithm for solving problems of onshore reservoir description is observed [6] [7] [8]. The aim of this study is to characterize target offshore reservoir with the integrated method of data mining and flow unit identification, and core samples were taken from Beibu Gulf typical low permeability operating area.

\section{Data Analysis Approach}

Hydraulic flow unit, has been well known as a part of the reservoir porous media, characterizes lateral and vertical consistency in reservoir rock and fluid properties. Lots of definitions for the unit were brought forward in the last decades by Hearn et al. [9], Ebanks [10] and Gunter et al. [11]. It was pointed out that the unit is useful in the reservoir characterization as it combines the most important two petrophysical properties: permeability and porosity. These two properties control reservoir quality in terms of reservoir storativity and transmissibility. In 1993, Amaefule et al. [12] presented the mathematical model for the $R Q I$ (Equation (1)) as:

$$
R Q I=0.0314 \sqrt{\frac{k}{\phi_{e}}}
$$

where $k$ is permeability $(\mathrm{mD}), \phi_{e}$ is effective porosity (fraction), and $R Q I$ is Reservoir Quality Index $(\mu \mathrm{m})$.

Different RQIs could be a signification for the existence of multiple flow units in the porous media which inevitably influences the expected pressure profiles and flow regimes. In following equations $\phi_{z}$ (Equation (2)) and FZI (Equation (3)) are normalized porosity index and Flow Zone Indicator $(\mu \mathrm{m})$ respectively. 


$$
\begin{gathered}
\phi_{z}=\frac{\phi_{e}}{1-\phi_{e}} \\
F Z I=\frac{1}{\sqrt{F_{s}} \tau S_{g v}}=\frac{R Q I}{\phi_{z}}
\end{gathered}
$$

This model system is based on texture and mineralogy which defines similar fluid flow features that is independent of lithofacies. Authors give an equation which is rearranged to isolate the variable that is constant within a unit based on the concept of bundle of capillary tubes [13].

\section{Flow Unit Division and Characterization}

\subsection{Flow Unit Division}

The division and characterization of the hydraulic flow units can be executed either using the static based or the dynamic based methodology. The common static methods include developing relationship between fluid properties and rock media by core and/or log derived data, and the statistical measurement of permeability and the heterogeneous degree of the reservoir. It has been found that the application effects of single parameter methods are poor, loyalties of results are not high. Considering natural distribution characteristics of porous media itself, clustering analysis was chosen to execute early classification with the Flow Zone Indicator and its related parameters; then the final classification was completed according to the clustering pedigree chart of hydraulic unit samples [14].

Flow Zone Index and the factor which reflects the features of microscopic pore structure have high correlation by analyzing the relationship between flow parameter and displacement pressure $\left(P_{d}\right)$. Besides, geological parameters for low permeability reservoirs were selected as clustering (Ward's method) variables: $\phi_{e}, \phi_{z}$ and $R Q I$. Sum of squares method which could deal with isolated points reasonably was considered preferentially. Based on the homogeneity of similar samples, 4 schemes were built finally (FU\#5, FU\#6, FU\#7, FU\#8).

\subsection{Data Mining for Flow Unit Characterization}

Due to the differentiation between petrophysical and percolation characteristics, there are some differences on logging response for each category of hydraulic flow unit, and based on the differences, a data mining method was also applied for identify the hydraulic unit of uncored intervals in the crossplot of logging bins. Key link of the whole system is probability database (include core and logging data), its construction process is through comparing each sample data and selecting logging parameters associated with the core. The database consisting of probability of occurrence for each unit corresponding to discretized logging data is assigned to all FUs. Basic computation of the database and inference of FUs was executed by self-software. Meanwhile, back evaluation program was performed to test the software's effect for known categories of cored interval. The software design procedure is presented in Figure 1. 
Probability database of cored sample unit categories were calculated after software debugging completed, and named as $\mathrm{P}_{\mathrm{FU} 5-1}, \mathrm{P}_{\mathrm{FU} 5-2}, \mathrm{P}_{\mathrm{FU} 5-3} ; \mathrm{P}_{\mathrm{FU} 6-1}, \mathrm{P}_{\mathrm{FU} 6-2}$, $\mathrm{P}_{\mathrm{FU} 6-3} ; \mathrm{P}_{\mathrm{FU} 7-1}, \mathrm{P}_{\mathrm{FU7}-2}, \mathrm{P}_{\mathrm{FU} 7-3} ; \mathrm{P}_{\mathrm{FU} 8-1}, \mathrm{P}_{\mathrm{FU} 8-2}, \mathrm{P}_{\mathrm{FU} 8-3}$. The result of back evaluation report shows that the accurate rates of $\mathrm{P}_{\mathrm{FU} 5-3}$ and $\mathrm{P}_{\mathrm{FU} 6-3}$ are better than remaining database (Table 1).

\subsection{Comparative Verification}

The predicted results of software were compared with the mature commercial system results of artificial neural network recognition mode for verifying its application. Firstly, the same cored single well and database $\mathrm{P}_{\mathrm{HU} 5-3}$ which has the higher accurate rate were choose, and then operated software, result of prediction rate was $82.07 \%$. Then selecting 5 typical logging parameters to be neural network input parameters, and the categories of hydraulic flow unit were selected as the parameter of expectation output, hidden layer neurons number range of $4-12$ and the output type is hydraulic flow unit. In the training process, the network learning rate is 0.05 , permissible error is 0.001 , and maximum number of iterations is 10000 . The number of hidden layer nodes selected by experience formula, network error showed the minimum error when the number of the nodes reach 11, then supplied single well data, we focus on the training error has reached the requirements when the number of iterations up to 5968 times (Table 2). Weights and thresholds of prediction model were created. The true positive rates of receiver operating characteristic curve increase fast, curves bent upward, areas under curve large, classified performance of model is favorable. Calling learning network to carry out predictive instruction for verified well, the final accuracy rate is $82.97 \%$, close to the predictive results with our software.

Table 1. Statistical results of back evaluation report on cored single wells.

\begin{tabular}{cccc}
\hline Database & Case 1 & Case 2 & Case 3 \\
\hline $\mathrm{P}_{\text {HU5-1 }}$ & 0.71 & 0.65 & 0.62 \\
$\mathrm{P}_{\text {HU5-2 }}$ & 0.63 & 0.77 & 0.72 \\
$\mathrm{P}_{\text {HU5-3 }}$ & 0.79 & 0.82 & 0.83 \\
$\mathrm{P}_{\text {HU6-1 }}$ & 0.77 & 0.75 & 0.79 \\
$\mathrm{P}_{\text {HU6-2 }}$ & 0.45 & 0.57 & 0.64 \\
$\mathrm{P}_{\text {HU6-3 }}$ & 0.83 & 0.78 & 0.79 \\
$\mathrm{P}_{\mathrm{HU7-1}}$ & 0.75 & 0.61 & 0.49 \\
$\mathrm{P}_{\mathrm{HU7-2}}$ & 0.62 & 0.67 & 0.39 \\
$\mathrm{P}_{\mathrm{HU7-3}}$ & 0.58 & 0.49 & 0.45 \\
$\mathrm{P}_{\text {HU8-1 }}$ & 0.77 & 0.75 & 0.73 \\
$\mathrm{P}_{\text {HU8-2 }}$ & 0.69 & 0.74 & 0.62 \\
$\mathrm{P}_{\text {HU8-3 }}$ & 0.44 & 0.51 & 0.59 \\
\hline
\end{tabular}




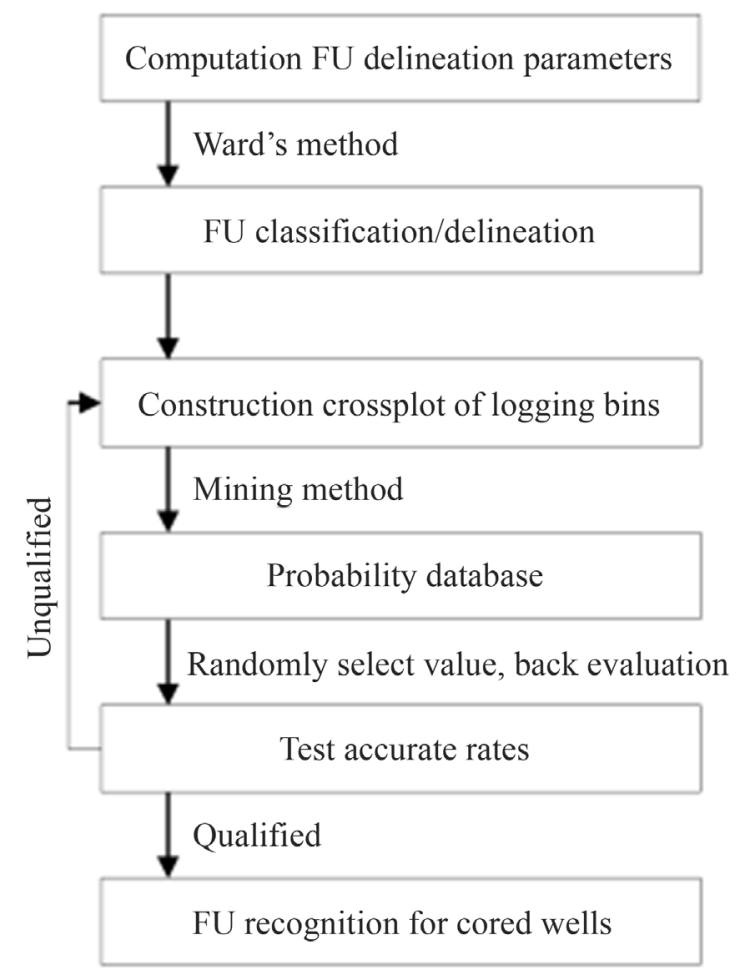

Figure 1. Compiling flowchart of FU recognition system.

Table 2. Input parameters and calculated process factors.

\begin{tabular}{ccccccc}
\hline \multicolumn{2}{c}{ Sample Weights } & $\begin{array}{c}\text { Network } \\
\text { Learning Rate }\end{array}$ & $\begin{array}{c}\text { Permissible } \\
\text { Error }\end{array}$ & $\begin{array}{c}\text { Maximum } \\
\text { Number of } \\
\text { Iterations }\end{array}$ & $\begin{array}{c}\text { Number of } \\
\text { Hidden Layer } \\
\text { Nodes }\end{array}$ \\
\hline 0.7 & 0.2 & 0.1 & 0.05 & 0.001 & 10000 & 11 \\
\hline
\end{tabular}

\section{Conclusion}

In this work, hydraulic flow units are delineated, and predicted from well loggings and validated on the basis of data mining method, reservoir performance, petrophysical properties and lithology. At the same time, the software was written in the prediction process, and the results were compared with the mature commercial system results for verifying its application. This study proves that in the offshore system of low permeability, utilizing the integrated method of data mining and flow unit identification could reach higher accurate rate on the prediction of uncored intervals. The same way could be promoted on several trial blocks with similar regional geological background.

\section{Acknowledgements}

This work was financially supported by The Guangxi Natural Science Foundations (2016GXNSFBA380180, 2017GXNSFAA198105), The Guangxi Education Department Scientific Research Project (2017KY0792), The Beibu Gulf University Scientific Research Project (2016PY-GJ09), The Opening Project of Guangxi Colleges and Universities Key Laboratory of Beibu Gulf Oil and Natural Gas 
Resource Effective Utilization (2016KLOG01, 2017KLOG25).

\section{Conflicts of Interest}

The author declares no conflicts of interest regarding the publication of this paper.

\section{References}

[1] Prasad, M. (2003) Velocity-Permeability Relations within Hydraulic Units. Geophysics, 68, 108-117. https://doi.org/10.1190/1.1543198

[2] Svirsky, D., Ryazanov, A., Pankov, M., Corbett, P. and Posysoev, A. (2004) Hydraulic Flow Units Resolve Reservoir Description Challenges in a Siberian Oil Field. SPE Asia Pacific Conference on Integrated Modelling for Asset Management, Kuala Lumpur, 29-30 March 2004, 1-15. https://doi.org/10.2118/87056-MS

[3] Amabeoku, M., Kersey, D., Bin Nasser, R., Al-Waheed, H. and Al-Belowi, A. (2005) Incorporating Hydraulic Units Concepts in Saturation-Height Modeling in a Gas Field. SPE Asia Pacific Oil and Gas Conference and Exhibition, Jakarta, 5-7 April 2005, 1-17. https://doi.org/10.2118/93763-MS

[4] Crandall, D., Bromhal, G. and Karpyn, Z.T. (2010) Numerical Simulations Examining the Relationship between Wall-Roughness and Fluid Flow in Rock Fractures. International Journal of Rock Mechanics and Mining Sciences, 47, 784-796. https://doi.org/10.1016/j.ijrmms.2010.03.015

[5] Abbaszadeh, M., Fujii, H. and Fujimoto, F. (1996) Permeability Prediction by Hydraulic Flow Units-Theory and Applications. SPE Formation Evaluation, 11, 263-271. https://doi.org/10.2118/30158-PA

[6] Aminian, K., Ameri, S., Oyeerokun, A. and Thomas, B. (2003) Prediction of Flow Units and Permeability Using Artificial Neural Networks. SPE Western Regionall AAPG Pacific Section Joint Meeting, Long Beach, 19-24 May 2013, 1-7. https://doi.org/10.2118/83586-MS

[7] Perez H.H., Datta-Gupta, A. and Mishra, S. (2005) The Role of Electrofacies, Lithofacies, and Hydraulic Flow Units in Permeability Predictions from Well Logs: A Comparative Analysis Using Classification Trees. SSPE Reservoir Evaluation \& Engineering, 8, 143-155. https://doi.org/10.2118/84301-PA

[8] Ali, S.S., Nizamuddin, S., Abdulraheem, A., Hassan R.M. and Hossain, E.M. (2013) Hydraulic Unit Prediction Using Support Vector Machine. Journal of Petroleum Science and Engineering, 110, 243-252. https://doi.org/10.1016/j.petrol.2013.09.005

[9] Hearn, C.L., Ebanks, W.J.J. and Ranganathan V. (1984) Geological Factors Influencing Reservoir Performance of the Hartzog Draw Field Wyoming. Journal of Petroleum Technology, 36, 1335-1344. https://doi.org/10.2118/12016-PA

[10] Ebanks W.J.J. (1987) Flow Unit Concept: An Integrated Approach to Reservoir Description for Engineering Projects. AAPG Bulletin, 71, 551-552.

[11] Gunter, G.W., Finneran, J.M. and Hartmann, D.J. (1997) Early Determination of Reservoir Flow Units Using an Integrated Petrophysical Method. SPE Annual Technical Conference and Exhibition, San Antonio, 5-8 October 1997, 1-8. https://doi.org/10.2118/38679-MS

[12] Amafule, J.O., Altunbay, M., Tiab, D., Kersey, D.G. and Keelan, D.K. (1993) Enhanced Reservoir Description: Using Core and Log Data to Identify Hydraulic (Flow) Units and Predict Permeability in Uncored Intervals/Wells. SPE Annual Technical Conference and Exhibition, Houston, 3-6 October 1993, 205-220. 
[13] Yarmohammadi, S., Kadkhodaie-Ilkhchi, A., Rahimpour-Bonab, H. and Shirzadi, A. (2014) Seismic Reservoir Characterization of a Deep Water Sandstone Reservoir using Hydraulic and Electrical Flow Units: A Case Study from the Shah Deniz Gas Field, the South Caspian Sea. Journal of Petroleum Science and Engineering, 118, 52-60. https://doi.org/10.1016/j.petrol.2014.04.002

[14] Aguilar, C., Govea, H. and Rincon, G. (2014) Hydraulic Unit Determination and Permeability Prediction Based on Flow Zone Indicator Using Cluster Analysis. SPE Latin American and Caribbean Petroleum Engineering Conference, Maracaibo, 21-23 May 2014, 1-13. https://doi.org/10.2118/169307-MS 